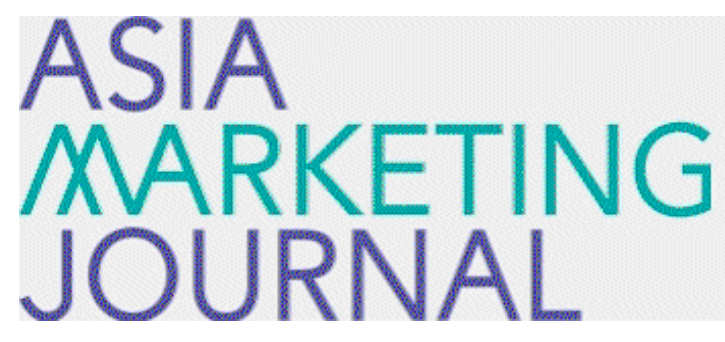

ASIA MARKETING JOURNAL

Volume 17 | Issue 4

Article 5

$1-31-2016$

\title{
Distribution Channel, Matching, and Welfare Asymmetry in the Korean Insurance Industry
}

Yong-Ju Lee

Follow this and additional works at: https://amj.kma.re.kr/journal

Part of the Marketing Commons

\section{Recommended Citation}

Lee, Yong-Ju (2016) "Distribution Channel, Matching, and Welfare Asymmetry in the Korean Insurance Industry," Asia Marketing Journal: Vol. 17 : Iss. 4 , Article 5.

Available at: https://doi.org/10.15830/amj.2016.17.4.89

This Article is brought to you for free and open access by Asia Marketing Journal. It has been accepted for inclusion in Asia Marketing Journal by an authorized editor of Asia Marketing Journal. 


\section{Distribution Channel, Matching, and Welfare Asymmetry in the Korean Insurance Industry: A Hint from Matching Theory}

Based on the observation that insurance companies in Korea, unlike those in other financial sectors and those in other countries, dominantly use the agent-based push-type marketing strategy, this paper hypothesizes that difference in distribution systems originating from characteristics of financial products can lead to welfare asymmetry between financial institutions and customers, merely due to their financial matching. For this analysis, we employ a simple matching theoretic model, try to understand the welfare implications of distribution systems from a matching theoretic perspective, and analyze the bottom of negative perceptions of insurance industry. The proposed model suggests that this welfare asymmetry derives mainly from financial matching through the distribution systems, which implies that any efforts to improve the insurance industry must consider changes in the matching process, namely the distribution system. We hope that this paper complements and extends the existing literature on insurance distribution systems in terms of methodologies and research subjects.

Key words: Distribution Systems, Financial Matching, Welfare Asymmetry, Insurance Industry

\section{Introduction}

One of the most serious issues in the Korean financial industry is its negative perception of finance and financial services institutions and this issue has been a matter of grave concern for senior managers and policymakers. This problem is urgent particularly in the insurance industry. For instance, as shown in Figure 1, the Customer Experience Index (CEI) for Korea (60.9 in 2012 and 62.8 in 2013) is far lower than the global average (67.5 in 2012 and 69.4 in 2013). In addition, the measure of customer trust (3.72) in the insurance industry is lower than that (4.1) in the banking industry (Figure 2).

\footnotetext{
* Assistant Professor, School of Economics and Finance, Yeungnam University (yongjulee@ynu.ac.kr)
} 
〈Figure 1〉 The Customer Experience Index (CEI), by country (2012-2013)

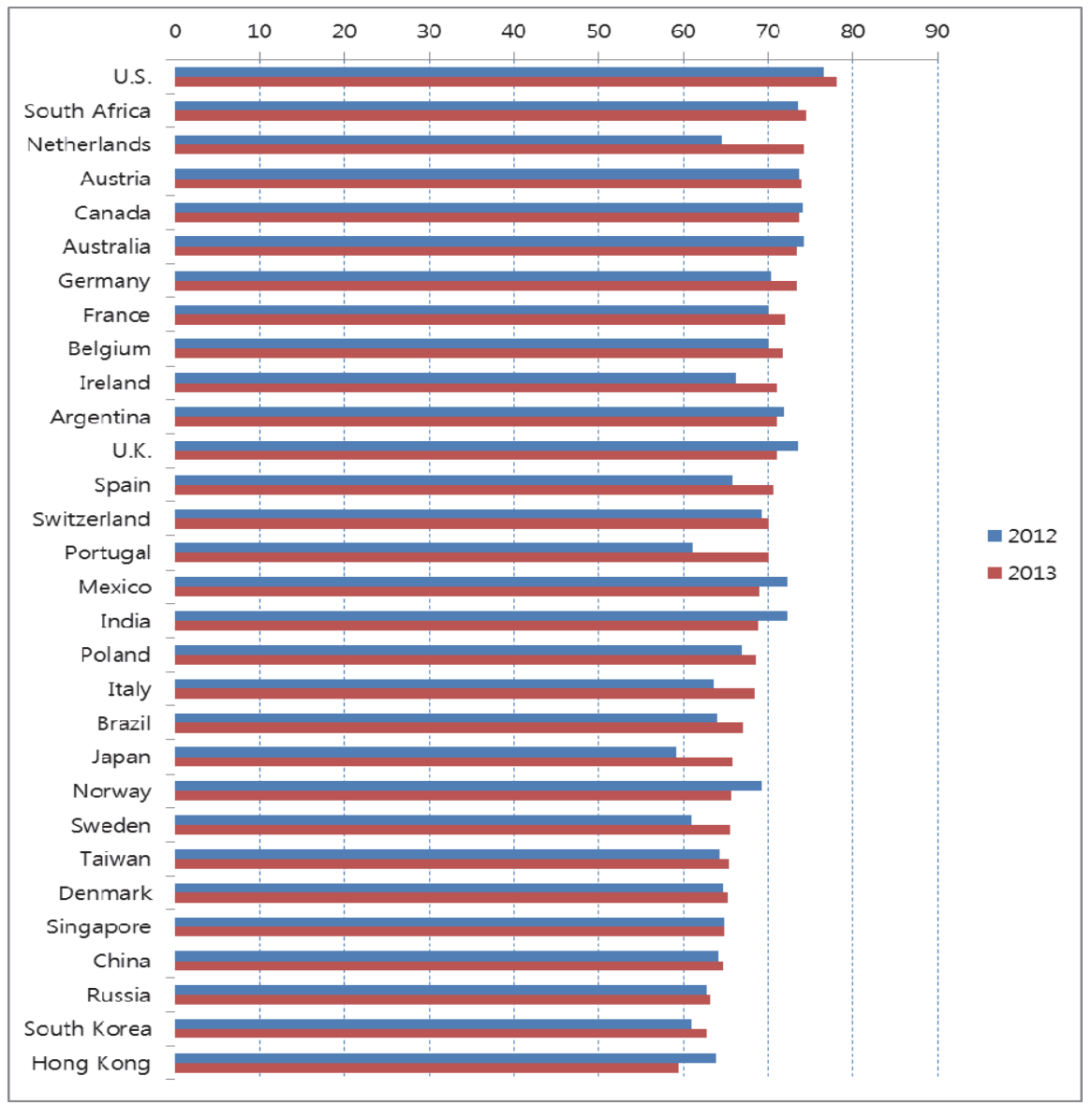

Source: Capgemini's (2014) World Insurance Report.

Unfavorable judgments about insurance companies clearly stem from bad practices, such as unsatisfactory claim services, sticky-down discount rates, a refusal to accept customers in need of insurance services, and unfair practices such as collusion among insurance companies, among others. However, it remains unclear whether these are really the main source of unfavorable perceptions because such bad practices can be easily found in other financial $\mathrm{sec}^{-}$ tors and have been corrected over a long period of time. That is, there may be something fundamental beyond the usual explanation and therefore the following question motivates this study: What is in the fundamental cause of negative views on insurance and the insurance industry?

The insurance industry differs from other financial industries in many dimensions, particularly in terms of product distribution systems. 
〈Figure 2〉 Customer trust

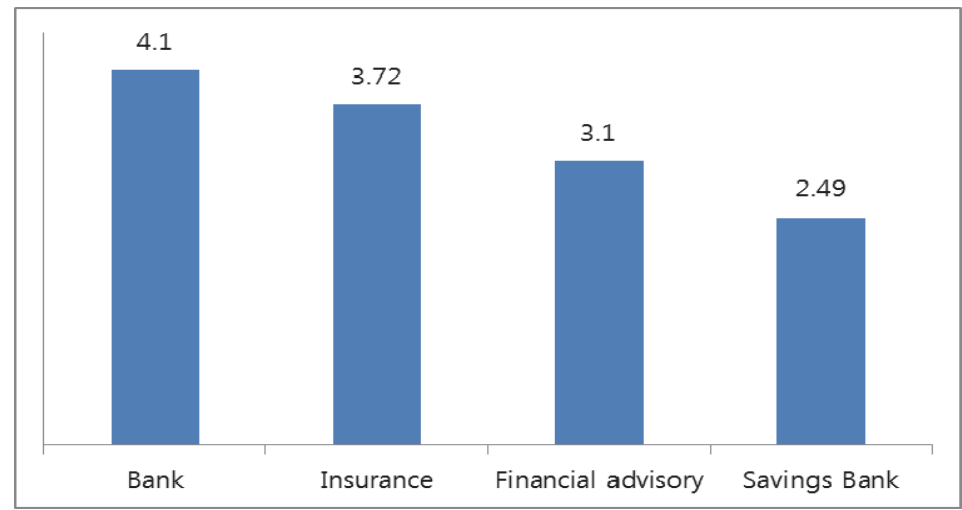

Source: The Korea Insurance Research Institute (2013. N=1,200, out of 5)

A wide variety of distribution methods have been used in the insurance industry, including the use of a professional employee sales force, independent sales representatives, and direct response methods such as mail and telephone solicitation. However, one common characteristic is that distribution methods represent the instrument of positive "solicitation" by insurance companies. The ongoing technological revolution in the financial services industry has led to substantial change in the distribution system, but this typical characteristic of company-solicitation marketing methods remains dominant in the Korean insurance industry.

This characteristic, which derives from characteristics of insurance products, can become clearer if insurance companies are compared with banks. Quality characteristics of insurance products (i.e., policies) are difficult to ascertain due to the complexity of contracts, the contingent nature of many services (e.g., claim handling and payment), and the fact that many services are provided over time. This implies that the quality of insurance products is difficult to ascertain in advance of their purchase and this may be so even after customers build substantial product experience. On top of consumers' limited opportunities to observe many aspects of product quality, the nature of insurance policies and their pricing is such that information may be difficult to compare across consumers. Given this circumstance, customers are not likely to have favorable purchase intentions toward insurance products, and insurance providers may have no choice but to engage in "push-type" marketing. ${ }^{1)}$ In addition,

1) Marketing theory distinguishes between two main types of promotional strategies; "push" and "pull." The "push-type" strategy makes use of a company's sales force and trade promotion activities to directly create consumer demand for a product. On the other hand, a "pull-type" strategy requires high spending on advertising and consumer promotion to build consumer demand for a product. 
because of consultation required before the purchase and regular advisory services required over the contract period, agent-based distribution systems have traditionally been advantageous for both sides. For this reason, this study defines the insurance industry to have a companyproposing characteristic, in which companies first approach target customers and then persuade them to buy products. On the other hand, banks employ "pull-type" marketing strategies by showing the comparative advantage of their products and inducing customers to buy their products. Because products of banks are relatively simple to understand by customers, branchbased distribution channels have traditionally been considered a typical distribution system. Table 1 summarizes these arguments.

This study examines the effects of these characteristics of insurance products and distinct marketing strategies on customer welfare. For this purpose, the study provides important welfare implications of financial matching characterized by distribution systems from the per- spective of matching theory and discusses the reason behind negative perceptions of insurance. Our hypothesis is that differences in distribution systems from characteristics of products, in the financial industry produce welfare asymmetry between financial institutions and their customers. Figure 3 illustrates this logic.

In addition, what is the relationship between matching theory and insurance? How can this study be matched to the insurance industry? At first glance, these two fields seem s to have no relationship. However, a simple model based on matching theory, so-called two-sided matching, has a profound implication on the insurance industry, particularly on that of Korea. This approach may inspire policymakers and top managers of insurance companies struggling to cope with deep-seated negative views on insurance.

This study contributes to the literature by suggesting and illustrating a new approach to the analysis of the financial distribution system and its effects on welfare asymmetry in the financial industry. The existing insurance liter-

〈Table 1〉 Insurance companies Vs. banks

\begin{tabular}{l|l|l}
\hline & \multicolumn{1}{|c}{ Insurance companies } & \multicolumn{1}{c}{ Banks } \\
\hline $\begin{array}{l}\text { Properties of products } \\
\text { Typical examples } \\
\begin{array}{l}\text { Complexity of products } \\
\text { Recognition of product utility }\end{array}\end{array}$ & $\begin{array}{l}\text { health insurance, life insurance } \\
\text { highly complex } \\
\text { contingent on the event }\end{array}$ & $\begin{array}{l}\text { deposits and loans } \\
\text { relatively simple and automatic } \\
\text { on a real time basis }\end{array}$ \\
\hline Marketing type & $\begin{array}{l}\text { Push-type } \\
\text { (approach and persuade) }\end{array}$ & $\begin{array}{l}\text { Pull-type } \\
\text { (show and attract) }\end{array}$ \\
\hline Traditional distribution channel & Agent-based & Branch-based \\
\hline Matching procedure & Company-proposing & Customer-proposing \\
\hline
\end{tabular}


〈Figure 3〉 Welfare implications of the insurance distribution system

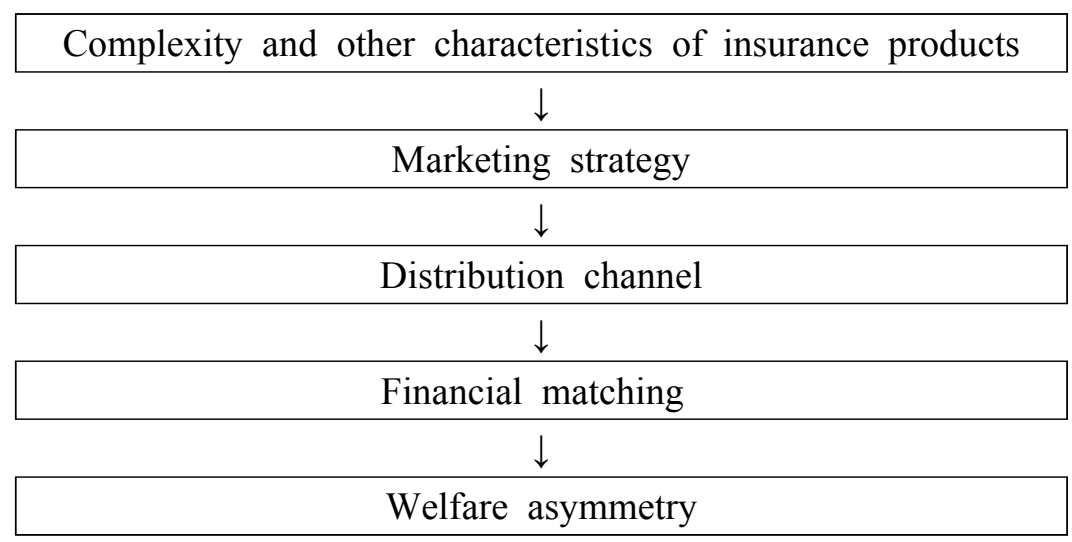

ature has analyzed insurance distribution systems based on three major economic issues: the problem of distribution system choice, the nature of the insurer-agent relationship (the principal-agent problem), and regulatory issues in insurance distribution activities (Etgar (1976), Berger et al. (1997) Dionne (2000), Klumpes and Stefan (2011)). The marketing literature has examined the concept of trust in the context of channel management and focused on measuring trust in the relationship between salespeople and customers in the service sector (Dwyer et al. (1987), Andaleeb (1992), Ganesan (1994), Doney and Cannon (1997), Fletcher and Peters (1997)). This study complements and extends the existing literature on insurance distribution systems in terms of methodologies and research subjects. Although this study does not consider classical topics, it demonstrates the wide applicability of matching theory to seemingly unrelated topics through a simple model. In addition, it illustrates a new stream of re- search on matching theory.

This paper makes some meaningful contributions from policy-related, regulatory aspects. The results show that there is more to something than meets the eye by demonstrating that customers face welfare asymmetry without realizing it. The proposed model illustrates that this welfare asymmetry originates mainly from the financial matching protocol through distribution systems, which implies that any efforts to improve the insurance industry should consider changes in the matching process, namely the distribution system.

The rest of this paper is organized as follows. Section 2 introduces the simple theoretic model, namely the marriage model, which describes the simple matching process between insurance companies and customers in the market. Section 3 extends to insurance market and discusses important implications. Section 4 concludes with a discussion of recent trends in the insurance market and their implications for insurance dis- 
tribution systems.

\section{Summary of the Literature}

This section examines the simplest form of the matching market, which is often referred to as the "marriage model." This section provides a systematic summary of the existing literature on matching theory, which is closely related and applicable to the insurance market in Korea. There appears to be no relationship between marriage and insurance, but from the perspective of matching theory, there may be an argument based on the fact that both are obviously involved in two-sided matching. Twosided matching is involved in markets with two sides that require matching with each other, such as firms and workers, students and schools, and men and women. A marriage market is briefly described based on Roth and Sotomayor (1992), and then the results applicable to the explanation of financial matching in the insurance market are discussed. Although the marriage model is a simple model that enables direct conclusions about the insurance market, its applicability becomes clear through an analysis of the insurance market later.

Based on Roth and Sotomayor (1992), a specific marriage market is denoted by the triple $\{\mathrm{M}, \mathrm{W}: \mathrm{P}\}$, where $\mathrm{M}=\left\{\mathrm{m}_{1}, \mathrm{~m}_{2}, \mathrm{~m}_{3}, \cdots, \mathrm{m}_{\mathrm{n}}\right\}$ is the set of men, and $\mathrm{W}=\left\{\mathrm{w}_{1}, \mathrm{w}_{2}, \mathrm{~W}_{3}, \cdots\right.$,
$\left.\mathrm{W}_{\mathrm{p}}\right\}$ is the set of women. Each man has preferences over women, and each woman has preferences over men. To express these preferences concisely, preferences of each man $\mathrm{m}_{\mathrm{i}}$ are represented by an order list of preferences, $\mathrm{P}\left(\mathrm{m}_{\mathrm{i}}\right)$, on the set $\mathrm{W} \cup\left\{\mathrm{m}_{\mathrm{i}}\right\}$. That is, preferences of $\mathrm{m}_{\mathrm{i}}$ may have the form $\mathrm{P}\left(\mathrm{m}_{\mathrm{i}}\right)=\mathrm{w}_{1}, \mathrm{w}_{2}, \mathrm{w}_{3}, \mathrm{~m}_{\mathrm{i}}$, $\mathrm{w}_{4}, \mathrm{~W}_{5}, \cdots, \mathrm{w}_{\mathrm{p}}$ indicating that his first choice is to be married to $\mathrm{w}_{1}$, his second choice is to married to $\mathrm{w}_{2}$, his third choice is $\mathrm{w}_{3}$, and his fourth choice is to remain single. Similarly, each woman $\mathrm{w}_{\mathrm{j}}$ has an ordered list of preferences, $\mathrm{P}\left(\mathrm{w}_{\mathrm{j}}\right)$, on the set $\mathrm{M} \cup\left\{\mathrm{w}_{\mathrm{j}}\right\}$. We will denote by $\mathrm{P}$ the set of preference lists $\mathrm{P}=\left\{\mathrm{P}\left(\mathrm{m}_{1}\right), \cdots\right.$, $\left.\mathrm{P}\left(\mathrm{m}_{\mathrm{n}}\right), \mathrm{P}\left(\mathrm{w}_{1}\right), \cdots, \mathrm{P}\left(\mathrm{w}_{\mathrm{p}}\right)\right\}$, one for each man and woman. We write $\left.\mathrm{w}_{\mathrm{i}}\right\rangle_{\mathrm{m}} \mathrm{w}_{\mathrm{j}}$ to mean $\mathrm{m}$ prefers $\mathrm{W}_{\mathrm{i}}$ to $\mathrm{W}_{\mathrm{j}}$. Economists customarily make two assumptions about the preferences of an individual. The first is that preferences are complete, which means that any two alternatives can be compared. The second is that the preferences are transitive, which means that if $A$ is preferred to $B$, and if $B$ is preferred to $C$, then $A$ is preferred to $C$. Preferences are called rational if the preferences possess these two properties. The question posed by the marriage model is then the following: Given the preferences of individuals involved, what type of outcome results from their collective interaction?

An outcome of the marriage model is a set of marriages. A matching $\mu$ is the one-to-one correspondence from the set $\mathrm{M} \cup W$ onto itself of order two such that if $\mu(\mathrm{m}) \neq \mathrm{m}$, then $\mu(\mathrm{m})$ 
$\in \mathrm{W}$, and if $\mu(\mathrm{w}) \neq \mathrm{W}$, then $\mu(\mathrm{w}) \in \mathrm{M}$. We refer to $\mu(x)$ as the mate of $x$. Each individual's preferences over alternative matchings correspond exactly to his or her preferences over his or her own mates at the two matchings. Therefore, $\mathrm{m}_{\mathrm{i}}$, say, prefers matching $\mu$ to matching $\nu$ if and only if he prefers $\mu\left(m_{\mathrm{i}}\right)$ to $\nu\left(\mathrm{m}_{\mathrm{i}}\right)$. Woman $\mathrm{w}$ is acceptable to man $\mathrm{m}$ if he likes her at least as well as remaining single. If an individual is not indifferent between any two acceptable alternatives, he or she has strict preferences. The matching $\mu$ is individually rational if each individual is acceptable to his or her mate. Consider a matching $\mu$ such that there exist a man $\mathrm{m}$ and a woman $\mathrm{w}$ who are not matched to one another at $\mu$, but who prefer each other to their mates at $\mu$. That is, suppose that $\mathrm{w}\rangle_{\mathrm{m}}$ $\mu(\mathrm{m})$ and $\mathrm{m}\rangle_{\mathrm{w}} \mu(\mathrm{w})$. The man and woman $(\mathrm{m}, \mathrm{w})$ will be said to block the matching $\mu$. This state of matching would be unstable in the sense that man $\mathrm{m}$ and woman $\mathrm{w}$ would have good reason to disrupt it in order to marry each other, and the rules of the game allow them to do so. A matching $\mu$ is stable if it is not blocked by any individual or any pair of individuals.

Before proceeding, there is a need to address the following fundamental question: Does stable matching always exist? Here the answer is affirmative. There always exists at least one matching that is stable. Although we can prove this in the rigorous manner, we illustrate it by an example. Suppose that men propose to women depending on their preferences and women are able to keep the best available man at any step engaged, without accepting him outright. Until the stable matching is made, this process continues.

Example. The set of preference lists, $\mathrm{P}=$ $\left\{\mathrm{P}\left(\mathrm{m}_{1}\right), \cdots, \mathrm{P}\left(\mathrm{m}_{\mathrm{n}}\right), \mathrm{P}\left(\mathrm{w}_{1}\right), \cdots, \mathrm{P}\left(\mathrm{w}_{\mathrm{p}}\right)\right\}$, is given. And suppose that proposals are made by men.

$$
\begin{aligned}
& \mathrm{P}\left(\mathrm{m}_{1}\right)=\mathrm{w}_{1}, \mathrm{w}_{2}, \mathrm{w}_{3}, \mathrm{w}_{4} \\
& \mathrm{P}\left(\mathrm{m}_{2}\right)=\mathrm{w}_{4}, \mathrm{w}_{2}, \mathrm{w}_{3}, \mathrm{w}_{1} \\
& \mathrm{P}\left(\mathrm{m}_{3}\right)=\mathrm{w}_{4}, \mathrm{w}_{3}, \mathrm{w}_{1}, \mathrm{w}_{2} \\
& \mathrm{P}\left(\mathrm{m}_{4}\right)=\mathrm{w}_{1}, \mathrm{w}_{4}, \mathrm{w}_{3}, \mathrm{w}_{2} \\
& \mathrm{P}\left(\mathrm{m}_{5}\right)=\mathrm{w}_{1}, \mathrm{w}_{2}, \mathrm{w}_{4} \\
& \mathrm{P}\left(\mathrm{w}_{1}\right)=\mathrm{m}_{2}, \mathrm{~m}_{3}, \mathrm{~m}_{1}, \mathrm{~m}_{4}, \mathrm{~m}_{5} \\
& \mathrm{P}\left(\mathrm{w}_{2}\right)=\mathrm{m}_{3}, \mathrm{~m}_{1}, \mathrm{~m}_{2}, \mathrm{~m}_{4}, \mathrm{~m}_{5} \\
& \mathrm{P}\left(\mathrm{w}_{3}\right)=\mathrm{m}_{5}, \mathrm{~m}_{4}, \mathrm{~m}_{1}, \mathrm{~m}_{2}, \mathrm{~m}_{3} \\
& \mathrm{P}\left(\mathrm{w}_{4}\right)=\mathrm{m}_{1}, \mathrm{~m}_{4}, \mathrm{~m}_{5}, \mathrm{~m}_{2}, \mathrm{~m}_{3}
\end{aligned}
$$

Step 1: $\mathrm{m}_{1}, \mathrm{~m}_{4}, \mathrm{~m}_{5}$ propose to $\mathrm{w}_{1}$, and $\mathrm{m}_{2}, \mathrm{~m}_{3}$ propose to $\mathrm{w}_{4}$. Here $\mathrm{w}_{1}$ rejects $\mathrm{m}_{4}$ and $\mathrm{m}_{5}$ and keeps $m_{1}$ engaged, and, $w_{4}$ rejects $m_{3}$ and keeps $\mathrm{m}_{2}$ engaged:

$\begin{array}{llll}\mathrm{W}_{1} & \mathrm{~W}_{2} & \mathrm{~W}_{3} & \mathrm{~W}_{4} \\ \mathrm{~m}_{1} & & & \mathrm{~m}_{2}\end{array}$

Step 2: $\mathrm{m}_{3}, \mathrm{~m}_{4}$, and $\mathrm{m}_{5}$ propose to their second choice, namely $\mathrm{w}_{3}, \mathrm{w}_{4}$, and $\mathrm{w}_{2}$, respectively; $\mathrm{w}_{4}$ rejects $m_{2}$ and keeps $m_{4}$ engaged:

$\begin{array}{llll}\mathrm{W}_{1} & \mathrm{w}_{2} & \mathrm{~W}_{3} & \mathrm{w}_{4} \\ \mathrm{~m}_{1} & \mathrm{~m}_{5} & \mathrm{~m}_{3} & \mathrm{~m}_{4}\end{array}$


Step 3: $\mathrm{m}_{2}$ proposes to his second choice, $\mathrm{w}_{2}$, who rejects $m_{5}$ and keeps $m_{2}$ engaged:

$\begin{array}{llll}\mathrm{w}_{1} & \mathrm{w}_{2} & \mathrm{w}_{3} & \mathrm{w}_{4} \\ \mathrm{~m}_{1} & \mathrm{~m}_{2} & \mathrm{~m}_{3} & \mathrm{~m}_{4}\end{array}$

Step 4: $\mathrm{m}_{5}$ propose to his third choice, $\mathrm{w}_{4}$, who rejects $m_{5}$ and continues with $m_{4}$ engaged. Since $m_{5}$ has been rejected by every woman on his list, he stays single, and the stable matching obtained is:

$\begin{array}{lllll}\mathrm{w}_{1} & \mathrm{w}_{2} & \mathrm{w}_{3} & \mathrm{w}_{4} & \left(\mathrm{~m}_{5}\right) \\ \mathrm{m}_{1} & \mathrm{~m}_{2} & \mathrm{~m}_{3} & \mathrm{~m}_{4} & \mathrm{~m}_{5}\end{array}$

Call this matching $\mu_{\mathrm{M}}$ to show that it is a result from the procedure where proposals are made by men.

Since men and women play precisely symmetrical roles in the marriage market, we could have described another way in which the roles of men and women were reversed. The stable matching obtained when the women propose to the men, denoted by $\mu_{\mathrm{W}}$, is

$\begin{array}{lllll}\mathrm{w}_{4} & \mathrm{w}_{1} & \mathrm{w}_{2} & \mathrm{w}_{3} & \left(\mathrm{~m}_{5}\right) \\ \mathrm{m}_{1} & \mathrm{~m}_{2} & \mathrm{~m}_{3} & \mathrm{~m}_{4} & \mathrm{~m}_{5}\end{array}$

Note in the Example that all men like $\mu_{\mathrm{M}}$ at least as well as $\mu_{\mathrm{w}}$, and all the women prefer $\mu_{\mathrm{W}}$ to $\mu_{\mathrm{M}}$. The observation in Example might just be an accident. It, however, turned out not to be an accident. This is one of the most surprising and important discoveries about the class of two-sided markets.

Definition. For a given marriage market $\{\mathrm{M}$, $\mathrm{W}: \mathrm{P}$, a stable matching $\mu$ is $\mathrm{M}$-optimal if every man likes it at least as well as any other stable matching; that is, if for every other stable matching $\mu^{\prime}, \mu \geq_{\mathrm{M}} \mu^{\prime}$. Similarly, a stable matching $\nu$ is $\mathrm{W}$-optimal if every woman likes it at least as well as any other stable matching; that is, if for every other stable matching $\nu, \nu \geq \geq_{\mathrm{W}} \nu^{\prime}$.

Each individual compares alternative matchings in terms of his or her preferences for his or her own mates at those matchings. Therefore, in examining the set of stable matchings, an individual is involved in comparing those mates whom he or she might have at some stable matching. Define a woman $\mathrm{w}$ and a man $\mathrm{m}$ to be achievable for each other in a marriage market $\{\mathrm{M}, \mathrm{W}: \mathrm{P}\}$ if $\mathrm{m}$ and $\mathrm{w}$ are paired at some stable matching.

Theorem 1 (Gale and Shapley, 1962). When all men and women have strict preferences, there always exists an M-optimal stable matching, and a W-optimal stable matching. Furthermore the matching $\mu_{\mathrm{M}}$ produced by ProposalEngagement-Marriage Procedure with men proposing is the Men-optimal stable matching. The W-optimal stable matching is the matching $\mu_{\mathrm{W}}$ produced when the women propose. 
Proof: When all men and women have strict preferences, ${ }^{2)}$ we will show that no man is ever rejected by an achievable woman. Consequently the stable matching $\mu_{\mathrm{M}}$ matches each man to his most preferred achievable woman, and is therefore the unique M-optimal stable matching.

The proof is by induction. Assume that up to a given step in the procedure no man has yet been rejected by a woman who is achievable for him. At this step, suppose woman w rejects man $m$. If she rejects $m$ as unacceptable, then she is unacceptable for him, and we are done. If she rejects $m$ in favor of man $m$, whom she keeps engaged, then she prefers $m$ ' to $m$. We must show that $\mathrm{w}$ is not achievable for $\mathrm{m}$.

We know m' prefers to $\mathrm{w}$ to any woman except for those who have previously rejected him, and hence are unachievable for him. Consider a hypothetical matching $\mu$ that matches $\mathrm{m}$ to $\mathrm{w}$ and everyone else to an achievable mate. Then $\mathrm{m}$ ' prefers $\mathrm{w}$ to his mate at $\mu$. So the matching $\mu$ is unstable, since it is blocked by $\mathrm{m}$ ' and $\mathrm{w}$, who each prefer the other to their mate $\mu$. Therefore there is no stable matching that matches $\mathrm{m}$ and $\mathrm{w}$, and so they are unachievable for each other, which completes the proof.
Thus, when preferences are strict, the individuals on one side of the market have a common interest regarding the set of stable matchings, since they are in agreement on the best stable matching. It turns out that individuals on the opposite sides of the market have opposite interests in this regard, and the optimal stable matching for one side of the market is the worst stable matching for individuals on the other side of the market. Let $\mu\rangle_{\mathrm{M}} \mu^{\prime}$ denote that all men like $\mu$ at least as well as $\mu^{\prime}$, with at least one man preferring $\mu$ to $\mu^{\prime}$ outright.

Theorem 2 (Knuth(1976). Recited from Roth and Sotomayor (1992)). When all individuals have strict preferences, the M-optimal stable matching is the worst stable matching for the women; that is, $\mu\rangle_{\mathrm{M}} \mu^{\prime}$ if and only if $\left.\mu^{\prime}\right\rangle_{\mathrm{W}} \mu$.

Proof: Let $\mu$ and $\mu^{\prime}$ be stable matchings such that $\mu>_{\mathrm{M}} \mu^{\prime}$. We will show that $\left.\mu^{\prime}\right\rangle_{\mathrm{W}}$ $\mu$. Suppose it is not true that $\left.\mu^{\prime}\right\rangle_{\mathrm{W}} \mu$. Then there must be some woman $\mathrm{w}$ who prefers $\mu$ to $\mu^{\prime}$. Then woman $\mathrm{w}$ has a different mate at $\mu$ and $\mu^{\prime}$, and consequently so does the man $\mathrm{m}=\mu(\mathrm{w})$. Since man $\mathrm{m}$ also has strict pref-

2) There are clearly many reasons to expect that agents may not have the ability to distinguish between all alternatives. Perhaps the most important reason is that agents may have little information on some alternatives, and thus are indifferent between them. However, in situations where agents have a great deal of information, we might even consider the case in which they have strict preferences to be typical. Loosely speaking, the reason is that indifference is in some sense a "knife-edge" phenomenon. That is, if an agent is indifferent between two alternatives, then a small improvement in one of them would presumably cause him or her to prefer it to the other. However, if an agent clearly prefers one alternative to another, then a sufficiently small improvement in the less preferred alternative will presumably leave preferences unchanged. In this sense, a situation with strict preferences is more robust and less special than that with indifference (Roth and Sotomayor (1992)). 
erences, $\mathrm{m}$ and $\mathrm{w}$ form a blocking pair for the matching $\mu$ '. This contradicts the assumption that $\mu^{\prime}$ is stable. Therefore $\left.\mu^{\prime}\right\rangle_{\mathrm{W}} \mu$, as required.

It should be noted that in Theorems 1 and 2 we have supposed that all individuals have strict preferences. If some individuals are indifferent between possible mates, we may introduce some fixed tie-breaking rule like alphabetical order of the name. Also we think that this assumption is neither a big restriction nor a special case. If an individual is indifferent between two alternatives, a small improvement in one of them would presumably cause him or her to prefer it to the other. Sometimes indifference is regarded as a knife edge phenomenon in this sense.

\section{Application to the Korean Insurance Market}

Consider informally the marriage model again. Suppose that two sets of individuals $\{I, C$ \} have strict preferences. Here those individuals in the set $I$ and told to "Point to your most preferred objects in the set $C$." Then they may point to more than one partner. However, suppose instead that they are told to "Be realistic, and point to your most preferred object among those who might actually agree to your pro- posal, given the competition among your set I." Here redefine the sets $\{I, C$. What happens if the set $I$ is a set of representative sales agent of insurance companies and the set $C$ is the set of insurance customers? Then turn to insurance matching between insurance companies and insurance customers. The objective of this section is to show that insurance market basically has properties of company-proposing model, and therefore produce company-optimal matching as defined above. For this purpose, there is a need to clearly answer to the questions of whether the marriage model is directly applicable to the insurance market and whether the results of the marriage model still remain valid. Surprisingly, as will be discussed later, arguments and results work in the same manner as in the marriage market.

\subsection{Application of the Marriage Model to the Insurance Matching}

As mentioned earlier, the insurance industry employs a typical company-solicitation, pushtype marketing strategy based on agent-based distribution systems. Although the ongoing technological revolution in the financial services industry has led to substantial change in distribution systems, the proposition that the insurance industry basically has properties of Company-proposing model is still dominant. Then there remain some theoretical issues on the application of the marriage model to the 
insurance market.

Consider the insurance market of a specific insurance product, not the whole insurance market. And let's think of a contract between a company and a customer as a matching between them. There are clear similarities between the insurance market and the simple marriage market. There are two types of players, companies and customers, and the function of the market is to match them. The major difference from the marriage model is that each insurance company can accommodate more than one customer, although each customer takes only one product. Assume that customers buy a single insurance policy for a single risk. That is, the insurance market is of many-to-one matching rather than one-to-one matching. This issue is easily overcome with a little computation. For this reason, we introduce a set of positive integers $\mathrm{q}(I)$ called the target sale quantity of company $I$, is introduced to indicate the optimally planned number of contracts it offers. ${ }^{3}$ A well-organized and profit maximizing insurance company must screen the potential population of insurance customers and set the target sales volume in advance. When we denote a particular company Ii, its target sale will be denoted $\mathrm{q}(i)$. An outcome of the insurance matching model is a matching of customers to companies, such that each customer is matched to at most one company, and each company is matched to around its target sales quantity of customers.

The second issue is that insurance companies are assumed to have preferences over individual customers. That is, they are able to rank order the customers who have applied to them for contracts. Insurance companies are publicly known to all customers, so each customer has preferences over insurance companies. But we should justify how companies have preferences over individual customers. First, suppose a pure theoretic market where sales agents and customers know each other, allowing for some conflict between the reality and theory. Historically insurance companies operated locally. Agents knew customers and their goal was to only insure people of sound health and of sober habit. Second, this assumption is fit for the existing market for new products where agents already own customers' list accumulated by the previous sales activities. Actually insurance companies compile tons of personal information on customers through several channels online or offline.) Thanks to the existence of several kinds of data collectors from whom insurance companies buy customer information, insurance companies compete against each other for common customers from the same database. If it is still unsat-

3) The simplest treatment is to set the target number to be equal to the number of the whole customers.

4) In the U.S., insurance companies can use several types of information: (1) customer's credit information from the credit bureaus such as Equifax, Experian, and TransUnion, (2) insurance claim information by data brokers, (3) health history information from sources such as the MIB consumer file database. 
isfactory, just assume that the model describe a local, or peculiar phenomenon, which is prevalent in Korea, where the troops of housewives working for insurance companies as a sales agent approach to acquaintances.

Although we have described companies' preferences over customers, each company with a target sales volume greater than one must be able to compare groups of students in order to compare alternative matchings as in the marriage model. Until we have described companies' preferences over matchings, our model will not be a well-defined game. So we should have defined the concept of responsive preferences over groups of customers. Surprisingly, however, it is well known that we will only need to assume that companies have strict preferences over individual customer, as in the marriage model. The reason for this is, even if it is not easy to understand, that when companies have strict preferences over customers, then they are not indifferent between any groups of customers assigned to them at stable matchings, even though they may be indifferent between other groups of customers. That is, if companies have strict preferences over individuals, then companies have strict preferences over those groups of customers that they may be assigned at stable matchings. (Roth and Sotomayor, 1989)
The last issue arises in the equilibrium concept. A matching $\mu$ is (pairwise) stable if it is not blocked by any individual player or any companycustomer pair. At a glance, it is not obvious that this definition will be adequate, since now we might consider coalitions consisting of a company and several customers, or even coalitions consisting of multiple companies and customers. We call a matching $\mu$ group stable if it is not blocked by any coalition.

Theorem 3. A matching is group stable if and only if it is (pairwise) stable.

Proof: If $\mu$ is unstable via an individual customer or company, or via a customer-company pair, then it is clearly group unstable via the coalition consisting of the same singleton or pair. In the other direction, if $\mu$ is blocked via coalition $\Omega$ and outcome $\mu^{\prime}$, let $I$ be in $\Omega$. Then the fact that $\left.\mu^{\prime}(I)\right\rangle_{I} \mu(I)$ implies that there exists a customer $c$ in $\mu^{\prime}(I)-\mu(I)$ and a $d$ in $\mu(I)-\mu^{\prime}(I)$ such that $\left.c\right\rangle_{I} d$. So $c$ is in $\Omega$ and $c$ prefers $I$ to $\mu(c)$, so $\mu$ is unstable via $C$ and $I$.

This says that the instabilities that can arise from coalitions of any size can be identified by examining only small coalitions. And more, it

5) Although our model takes the cooperative approach and employs the concept of stability as an equilibrium, our model can be easily transformed to a noncooperative game. So if the quota is big enough (even though smaller than the entire market), customer can be patient, i.e., wait until receiving offers from all companies. This should be customer's dominant strategy. 
says that stable and group stable matchings can be identified using only the preferences $\mathrm{P}$ over individuals, that is, without knowing the preferences $\mathrm{P}^{*}(I)$ that each company has over groups of customers.

All the issues examined above suggests that the insurance matching model may be very similar to the marriage model, and that many of the results obtained for the marriage model will generalize immediately to the insurance matching.

\subsection{A Related Marriage Market}

Consider a particular insurance matching problem in which companies $I=\left\{I_{1}, I_{2}, \cdots, I_{n}\right\}$ have target sales $\mathrm{q}(1), \mathrm{q}(2), \cdots, \mathrm{q}(n)$, and customers $C=\left\{C_{1}, C_{2}, \cdots, C_{p}\right\}$. Here the preferences of customers and companies over individuals are given by $\mathrm{P}=\left\{\mathrm{P}\left(I_{1}\right), \cdots, \mathrm{P}\left(I_{n}\right), \mathrm{P}\left(C_{1}\right), \cdots\right.$, $\left.\mathrm{P}\left(C_{\mathrm{p}}\right)\right\}$.

Now consider a related marriage market, in which each company $I$ with target sale $\mathrm{q}(I)$ is broken into $\mathrm{q}(I)$ pieces of itself such that in the related market, the players are customers and company positions, each having a target sale of one. That is, we replace company $I$ by $\mathrm{q}(I)$ positions of $I$ denoted by $i_{1}, i_{2}, \cdots, i_{\mathrm{q}}(I)$. Each of these positions has preferences over individual customers that are identical with those of $I$. Since each position $i$ has a target sale of one, we do not need to consider its preferences over group of customers. We have some lee- way in describing the preferences of the customers, who are in fact indifferent between the different positions at each company that are now each represented as a separate players. In order not to complicate the exposition about the results for which the assumption of strict preferences is important, we will assume that each customer's preference list is modified by replacing $I$, wherever it appears on his or her list, by the string $\dot{1}_{1}, \dot{1}_{2}, \cdots, \dot{1}_{\mathrm{q}(I)}$, in that order.

If the preferences over individuals are strict, then there is a natural one-to-one correspondence between matchings in the original insurance matching problem and matchings in the marriage market derived from it in this way. That is, a matching $\mu$ of the insurance matching problem, which matches a company $I$ with the customers in $\mu(I)$, corresponds to the matching $\mu^{\prime}$ in the related marriage market in which the customers in $\mu(I)$ are matched, in the order that they occur in the preferences $\mathrm{P}(I)$, with the ordered positions of $I$ that appear in the related marriage market. Thus a matching of the insurance matching problem is stable if and only if the corresponding matchings of the related marriage market are stable.

Differences between the insurance matching problem and the marriage market appear in different ways depending on whether results are viewed based on the structure of a set of stable matching. Since stable machings can be identified without regard to preferences of companies over groups of customers, we confine our 
attention to the set of stable matchings.

Now we are ready to establish some results for the insurance matching problem. We continue to assume that all preferences are strict. As in the marriage model, a matching mechanism in the related marriage market by deferred acceptance with company-proposing produces a company-optimal stable matching. Note again that we write $\mu\rangle_{I} \mu^{\prime}$ to mean $\mu(I) \geq_{I} \mu^{\prime}(I)$ for all $I \in I$ and then $\mu(I)\rangle_{I} \mu^{\prime}(I)$ for some $I \in I$.

Theorem 4. If $\mu$ and $\mu^{\prime}$ are stable matchings for $\{I, C$ : P $\}$ then $\mu\rangle_{I} \mu^{\prime}$ if and only if $\left.\mu^{\prime}\right\rangle_{C} \mu$.

Proof: Suppose that $\mu(I) \geq_{I} \mu^{\prime}(I)$ for all $I$ $\in I$ and $\mu(I)\rangle_{I} \mu^{\prime}(I)$ for some $I \in I$. This is equivalent to $\underline{\mu}\left(i_{n}\right) \geq i_{n} \underline{\mu^{\prime}}\left(i_{n}\right)$ for all $i_{n} \in$ $I^{\prime}$ and $\underline{\mu}\left(i_{m}\right)>i_{m} \underline{\mu}\left(i_{m}\right)$ for some $i_{m} \in I$, when $\underline{\mu}$ and $\underline{\mu}$ 'be the stable matchings corresponding to $\mu$ and $\mu^{\prime}$ in the related marriage market $\left\{I, C: \mathrm{P}^{\prime}\right\}$. This in turn is satisfied if and only if $\underline{\mu}\rangle_{I} \underline{\mu^{\prime}}$ and hence, if and only if $\left.\underline{\mu}^{\prime}\right\rangle_{C} \underline{\mu}$ by Theorem 3, which implies $\left.\mu^{\prime}\right\rangle_{C} \mu$.

This of course has the following immediate corollary.

Corollary 5. The optimal stable matching on one side of the market $\{I, C: P\}$ is the worst stable matching for the other.
The results specified above says that the insurance matching market with company-proposing produces a company-optimal stable matching, which is the worst stable matching for the customers. This completes the purpose of this paper.

\section{Conclusion}

Negative perceptions of insurance have been an important issue for senior managers of insurance companies as well as policymakers. However, this study shows that there is something else beyond the absolute level of bad practices. Based on the observation that insurance companies in Korea still make dominant use of agent-based push-type marketing strategy, we employ a matching theoretic model, and try to understand the welfare implications of insurance distribution systems from a matching theoretic perspective.

The results for the model indicate that welfare asymmetry in the insurance industry originates mainly from the financial matching process through the distribution system between customers and insurance companies. Then why does the insurance industry have this type of special distribution system? This study conjecture that this is due to characteristics of insurance products. Quality characteristics of insurance products are difficult to ascertain be- 
cause of the complexity of contract, the contingent nature of many services provided. Therefore, customers are reluctant to pay for some unrealized future risk. Given this circumstance, customers are not likely to move first to purchase insurance products, and insurance sellers may have no choice but to engage in "push-type" marketing. And thanks to both explanations needed before purchase and regular advisory services needed over the contract period, an agent-based distribution system has traditionally been advantageous.

This study makes some meaningful contributions to the literature from policy and regulatory perspectives. This study suggests that there is more to something than meets the eye by showing that customers face welfare asymmetry without even realizing it. This implies that efforts to improve in the insurance industry must consider changes in the matching process, namely the distribution system. That is, a regulatory policy must induce insurance companies to diversify their distribution systems away from agent-based ones, make insurance products easy to understand, and design products in the manner that customers can recognize their value of insurance products in their daily life. Recently two important trends are becoming visible in insurance marketing relationships: the use of multiple distribution systems within a single firm, and the increased specialization of roles of different distribution systems. The industry has started to move away from a set of fixed rela- tionships between insurers and agents based on industry traditions, toward more flexible systems in which distribution methods are determined by products and customer groups. In accordance with the development of platform businesses such as online marketing and independent agents, the use of company-proposing is likely to decrease in the near future. In this regard, future research should determine whether customers' negative perceptions decrease with the diversification of distribution systems. We leave this for future research.

This study makes another contribution to the literature by proposing and illustrating a new approach to the analysis of the financial distribution system and its effects on welfare in the industry. The study innovatively complements and extends the existing literature on insurance distribution systems in terms of methodologies and research subjects. To the authors' knowledge, no study has employed matching theory to analyze the insurance industry. In this regard, this study contributes to the literature by demonstrating the robust applicability of matching theory arguments to seemingly unrelated topics through a simple model and thus suggesting a new stream of research based on matching theory.

〈Received October 31. 2015〉

$\langle$ Revised December 15. 2015〉

$\langle$ Accepted January 20. 2016〉 


\section{References}

Andaleeb, S. (1992). The Trust Concept: Research Issues for Channel of Distribution. Research in Marketing, 11, 1-34.

Berger, A. N., Cummins, D., \& Weiss, M. A. (1997). The Coexistence of Multiple Distribution Systems for Financial Services: The Case of Property-Liability Insurance. Journal of Business, 70, 515-546.

Dionne, G. (2000). Handbook of Insurance, Kluwer Academic Publishers.

Doney, P., \& Cannon, J. (1997). An Examination of the Nature of Trust in Buyer-Seller Relashionships. Journal of Marketing, 61, $35-51$.

Dwyer, R., Schurr, P. \& Oh, S. (1987). Developing Buyer-Seller Relationships. Journal of Marketing, 5, 11-27.

Etgar, M. (1976). Service Performance of Insurance Distribution. Journal of Risk and Insurance, 43, 487-499.

Fletcher, K. \& Peters, L. (1997). Trust and Direct Marketing Environments: a Consumer Perspective. Journal of Marketing Management, 13, 523-539.
Gale, D. \& Lloyd, S. (1962). College admissions and the stability of marriage. American Mathematical Monthly, 69, 9-15.

Ganesan, S. (1994). Determinants of Long-Term Orientation in Buyer-Seller Relationships. Journal of Marketing, 58, 1-19.

Klumpes, P. \& Stefan, S. (2011). Corporate, Product and Distribution Strategies in the European Life Insurance Industry. Geneva Papers on Risk and Insurance-Issues and Practices, 36, 50-75.

Posey, L. \& Tennyson, S. (1998). The Coexistence of Distribution Systems under Price Search: Theory and some Evidence from Insurance. Journal of Economic Behavior and Organization, 35, 95-115.

Posey, L. \& Yavas, A. (1995). A Search Model of Marketing Systems in Property-Liability Insurance. Journal of Risk and Insurance, 62, 666-689.

Roth, A. \& Sotomayor, M. (1989). The college admissions problem revisited. Econometrica, 57, 559-570.

Roth, A. \& Sotomayor, M. (1992). Two-Sided Matching: A Study in Game-Theoretic Modeling and Analysis, Cambridge Press. World Insurance Report (2014), Capgemini. 